\title{
Evaluation of Turbulence Models and Wind Flow Behaviors around the Building
}

\author{
Thet Mon Soe ${ }^{1}$ and San Yu Khaing ${ }^{2}$ \\ Associate Professor ${ }^{1}$, Professor ${ }^{2}$ \\ Civil Engineering Department \\ Mandalay Technological University \\ Mandalay, Myanmar
}

\begin{abstract}
Wind loads are of important, particularly in the design of large structures. The wind velocity that should be considered in the design of structure depends upon the geological location and the exposure of the structure. Wind is a phenomenon of great complexity because of the many flow situations arising from the interaction of wind with structures. Wind conditions and wind flow patterns are strongly influenced by high-rise buildings and urban environment around buildings because of the many flow situations arising from the interaction of wind with structures. CFD (Computational Fluid Dynamics) simulation is the main research method for assessing the wind environment around building complexes. In this paper, a comparison of different turbulence models in simulating wind environment around building complexes is conducted to discuss their precision of simulation. Present work used a three dimensional scale down model of buildings where transient flow analysis has been done. It has been implemented through ANSYS Fluent 17.0 using SIMPLE algorithm as solver. In the present study a single high-rise building is considered and evaluated for three different turbulence models by using CFD simulation and is compared with the experimental results obtained from Tokyo Polytechnic University "New frontier of Education and Research in Wind Engineering" to validate CFD simulations. The existing cluster of building located in Mandalay is selected. Simulation observed that the layout of existing cluster of buildings is good enough for building planners to take critical decision such as exterior layout of building, building spacing by wind flow pattern except for $45^{\circ}$ wind angle. Before the initial stages of the building design, the layout of the buildings over the neighborhood is an important factor to control the wind field for urban planner.
\end{abstract}

Key Words: Computational fluid dynamics, Existing cluster of Building, Turbulence models, Wind flow patterns, Wind angles.

\section{INTRODUCTION}

Wind is an important issue on high-rise buildings. Wind causes aerodynamic pressures on the surfaces of the buildings. These wind induced aerodynamic pressures also vary randomly with time and space. There is a huge demand for high rise buildings in developing countries and developed countries. With the development in technology taller and taller structures are being designed and constructed to care of the local need and desire. Such structures have a significant effect on the surrounding wind patterns. High rise buildings in urban areas should be designed to ensure comfort of their inhabitants and users. The construction of a building inevitably changes the outdoor environment around the building. These changes include wind speed, wind direction, air pollution, driving rain and heat radiation. The change of these quantities depends on the shape, size and orientation of the building and on the interdependence of the buildings with surrounding buildings. This causes many environmental problems in nearby areas such as accelerated wind flow at the ground level impacting the comfort, and sometimes safety, of the users of the building 
and the pedestrians in the surrounding street canyons. For a safe structural design of any particular structure, it is necessary to consider wind effects. Although one cannot see the wind, it is a common observation that its flow is quite complex and turbulent in nature and has a tendency to exert differential velocity and pressure field around any obstacle likely to obstruct its flow path. The generalized estimation of wind loading is carried out by defining pressure coefficients. Pressure coefficients are nondimensional parameter which is used to assess magnitude. Pressure coefficients are influenced by various parameters like, shape, structural geometry, incident wind profile, terrain roughness, turbulence in the wind, location of a particular structure etc. [1].

CFD (Computational Fluid Dynamics) simulation methods are employed as the main methods for studying the outdoor wind environment today. The precision of simulation results is influenced by many factors, such as algorithms, boundary conditions and turbulence models. Due to the time and cost issues involved in wind tunnel testing, CFD is now widely employed for the prediction of flow fields. The first CFD techniques were introduced in the early 1950s, made possible by the advent of the digital computer [Chung, 2002]. CFD is a computer-based mathematical modeling tool capable of dealing with fluid flow problems and predicting physical fluid flows and heat transfer [2].

In Mandalay City, there are increasing numbers of high constructions and complex forms which can involve problems of significant wind discomfort around buildings. Designers and engineers should pay more attention in creating more comfortable and functional buildings and their surroundings. Pedestrian-level wind (micro)-conditions is one of the first microclimatic issues to be considered in modern city planning and building design. The construction of a new building alters the microclimate in its vicinity; hence wind comfort and safety for pedestrians become important requirements in urban planning and design. Today, some city authorities request studies of pedestrian wind comfort and safety for new buildings and new urban developments.

\section{METHODOLOGY}

When performing a simulation, the user typically chooses target variables, the approximate form of the governing equations, the turbulence model, and the level of detail in the geometrical representation of the buildings, the size of the computational domain, the type and resolution of the computational grid, the boundary conditions, the discretization schemes, and the iterative convergence criteria.

\subsection{Governing equations}

Wind engineers study more about the lower part of the atmosphere though entire earth atmosphere extends few kilometers above the earth surface. This lower part of the atmosphere is called as atmospheric boundary layer (ABL), which is directly under influence of earth surface itself such as shape, friction, thermal with time scales of less than a day and turbulent motion length scales of the order of boundary layer depth [3]. This boundary layer depth can be varying from several hundred meters to more than a kilometer aloft. Thus, most of manmade structures are well within the atmospheric boundary layer, governing flow equations can apply in this layer easily. Most of governing equations in fluid dynamics can be applied to the atmospheric flows. The main governing equations, about conservation of mass and momentum equations, are as follow.

$$
\begin{aligned}
& \frac{\partial \rho}{\partial t}+\frac{\partial\left(\rho u_{i}\right)}{\partial x_{i}}=0 \\
& \frac{\partial \rho u_{i}}{\partial t}+\frac{\partial\left(\rho u_{i} u_{j}\right)}{\partial x_{j}}=\frac{\partial P}{\partial x_{i}}+\frac{\partial}{\partial x_{j}}\left[\mu\left(\frac{\partial u_{i}}{\partial x_{j}}+\frac{\partial u_{j}}{\partial x_{i}}\right)\right]
\end{aligned}
$$

Where, $u_{i}, u_{j}$ are velocity components, $\rho$ is air density, $P$ is air pressure, $\mu$ is dynamic viscosity, and $t$ is time. In this equation, Coriolis force and buoyance force are not considered as their effect is negligible in smaller length and time scale, which is valid for micro-scale CFD simulations.

Two-equation models have been the most popular models for a wide range of engineering analysis and research. These models provide independent transport equations for both the turbulence length scale, or some equivalent parameter, and the turbulent 
kinetic energy. In this study, models have been selected for numerical simulation for wind load prediction using three different turbulence models which are standard k- $\varepsilon$ model, RNG k- $\varepsilon$ model and Realizable k- $\varepsilon$ model.

\subsection{Computational domain}

The size of computational domain in vertical, lateral and flow direction depends on the region that shall be represented by the simulation [4].Domain should be large enough to avoid reflecting of fluid streams, which may cause abnormal pressure field around the model. The blockage ratio should be below 3\% as suggested by Baetke and Werner is also a consideration for select size of the computational domain. For the single building model, lateral and top boundaries should be set $5 \mathrm{H}$ or more away from the building, where $\mathrm{H}$ is the high of the target building. The outflow boundary should be set at least $10 \mathrm{H}$ behind the building. Where the building surroundings are included, the height of the computational domain should be set to correspond to the boundary layer height determined by the terrain category of the surroundings [5]. The lateral size of the computational domain should extend about $5 \mathrm{H}$ from the outer edges of the target building.

However, recommendations of Franke [4] about laterals boundaries are 2 to 3 times B (where B is the width of built area) and outflow boundaries are $15 \mathrm{H}$ (where $\mathrm{H}$ is the height of the target building) is a conservative approach. It should be noted that there is a possibility of unrealistic results, if the computational region is expanded without proper representation of surrounding of the building. However, it is also true that unnecessary large fluid domain may demand higher computational cost.

\subsection{Meshing}

Meshing is another important stage of a CFD simulation, which corresponds to accurate simulation of the atmosphere boundary layer as well as fluid motion near the ground. Therefore, some of the meshing parameters such as first node height, number of nodes within boundary layer should be kept within certain limits in order to perform successful simulations [6]. In this study, this structured mesh has over 1230000 hexahedral cells with MultiZone Meshing Method. Structured mesh is more effective in cubic type models and gives undistorted flow conditions easily. The maximum cell size for all three domains was $0.05 \mathrm{~m}$ and minimum cell size was $0.001 \mathrm{~m}$.

\subsection{Boundary Condition}

Boundary conditions represent the influence of surroundings that have been cut off by the computational domain. The boundary conditions for inlet, outlet and outer walls should be provided [7]. The inlet boundary conditions of the domain are defined by the vertical profile. The inlet wind vertical profile is represented in the power law profile form

$$
U(z)=U_{r e f}\left(\frac{z}{z_{r e f}}\right)^{\alpha}
$$

where, $U(z)$ is the velocity at height $\mathrm{z}$ above the ground, $\mathrm{U}_{\text {ref }}$ the basic wind speed at reference height, $\mathrm{Z}_{\text {ref }}$ the reference height above the ground, generally $10 \mathrm{~m}$, and $\alpha$ is constant exponent power law, varying for different terrains.

\subsection{Numerical Setup}

CFD code Fluent v17 is used to solve the 3D Reynolds-Average Navier-Stokes (RANS) equations and continuity equation, using the finite volume method. Standard k- $\varepsilon$ model, RNG k- $\varepsilon$ model and Realizable k- $\varepsilon$ model with standard wall functions are used for turbulence modelling. SIMPLE algorithm is used for pressure-velocity coupling. As pressure based solver is used, secondorder upwind discretization schemes are used for the convection terms and the viscous terms of the governing equations, i.e. conservation of mass and momentum equations.

\section{VALIDATION ON CFD SIMULATION}

In this simulation, the aspect ratio of rectangular prism is $1: 3$ and the basic wind speed is considered $10.7535 \mathrm{~m} / \mathrm{s}$ which are similar to the values simulated in the wind tunnel. The building chosen for this work is a 1: 100 scale rectangular prism with a full scale size of $30.48 \mathrm{~m}(\mathrm{~L}) \times 30.48 \mathrm{~m}(\mathrm{~W}) \times 91.44 \mathrm{~m}(\mathrm{H})$. The arbitrary domain size shows in Figure 1 to simulate the building within the atmospheric boundary layer. The dimensions of the computational domain are $518.16 \mathrm{~m} \times 274.32 \mathrm{~m} \times 1097.28 \mathrm{~m}$ in 
lateral, vertical and flow directions respectively. These dimensions respected a $1.96 \%$ blockage ratio (ratio of the front area of the building over the inlet area).

In this study, meshing has over 1260000 nodes and over 1220000 elements by using MultiZone Meshing Method. The maximum cell size was $0.05 \mathrm{~m}$ and minimum cell size was $0.001 \mathrm{~m}$. The inflow wind velocity profile are computed by power law equation and imposed by UDF (C+ program). The vertical profile for inlet boundary condition is show in Figure 2 and the summary of the data required for computation through ANSYS FLUENT is shown in Table 1.

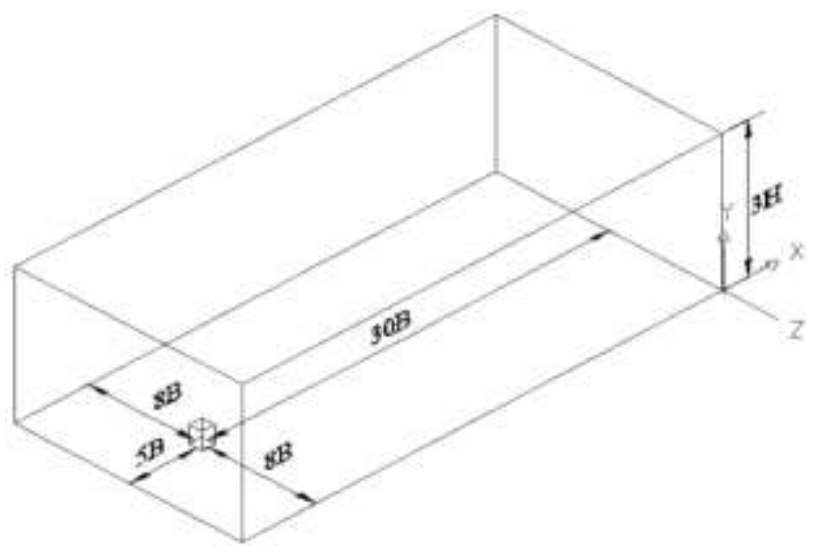

Figure 1. Arbitrary domain size

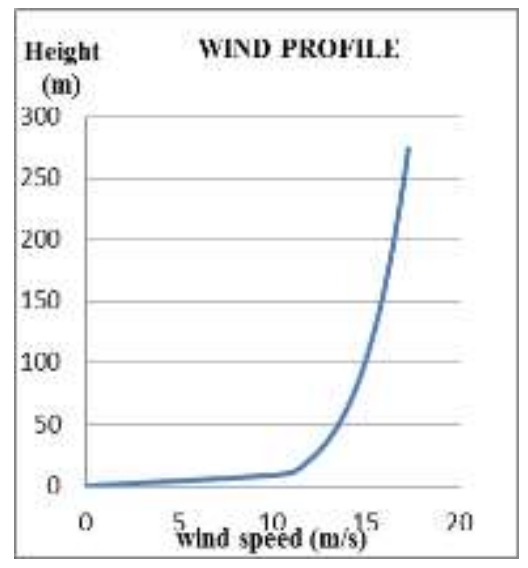

Figure 2. Vertical Profile For Inlet Boundary Conditions

Table 1. Input Parameter

\begin{tabular}{|c|c|c|}
\hline $\mathbf{S . N}$ & Parameters & Values \\
\hline 1 & Vertical Velocity Profile & $10.7535 \times\left(\frac{Z}{10}\right)^{1 / 7}$ \\
\hline 2 & Basic Wind Speed (m/s) & 10.7535 \\
\hline 3 & Power Law Coefficient, $\alpha$ & $1 / 7$ \\
\hline 4 & Turbulent Viscosity Ratio & 10 \\
\hline 5 & Density of air $\left(\mathrm{kg} / \mathrm{m}^{3}\right)$ & 1.225 \\
\hline 6 & Viscosity of air (kg/m-s) & $1.7594 * 10^{-5}$ \\
\hline 7 & Solver & Pressure -based steady state \\
\hline 8 & Models & $\begin{array}{c}\text { standard k- } \varepsilon \text { model, RNG k- } \varepsilon \text { model, Realizable k- } \varepsilon \\
\text { model }\end{array}$ \\
\hline 9 & Solution Method & SIMPLE pressure velocity coupling \\
\hline
\end{tabular}

\subsection{Comparison of pressure coefficients}

The present study a single high-rise building is considered and evaluated for three different turbulence models by using CFD simulation and is compared with the experimental results obtained from Tokyo Polytechnic University "New frontier of Education and Research in Wind Engineering" to validate CFD simulations. The pressure coefficients follow a similar trend with the wind tunnel results on the windward wall. Computational fluid dynamics simulations programs are also very powerful tools for modeling the wind around buildings. They give a quantitative and qualitative wind flow representation of the whole volume simulated. 


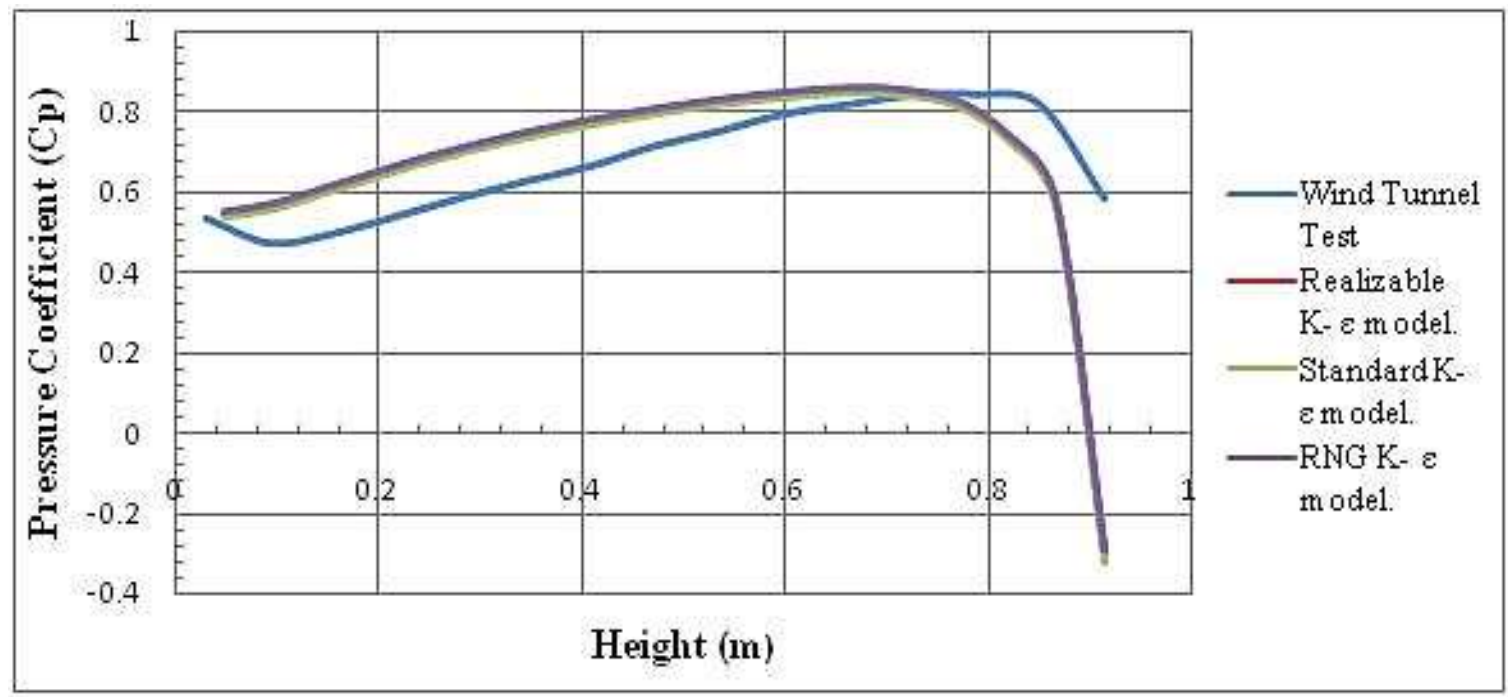

Figure 3. Comparison of pressure coefficients for the windward wall

The average wind pressure coefficient in the simulation result of the RNG k-E model is around 0.683 while that of the standard $\mathrm{k}-\varepsilon$ model is around 0.669 . For simulation results of the Realizable $\mathrm{k}-\varepsilon$ model, the average pressure coefficient is 0.675 . The wind pressure distribution in the simulation result of the three $\mathrm{k}-\mathcal{E}$ models are almost the same prediction. But, for the standard $\mathrm{k}-\varepsilon$ method, the value of average pressure coefficient is under predict while the RNG k-E model is over estimate compare to the wind tunnel result. As a conclusion, the Realizable k- $\varepsilon$ model performs better than the Standard k- $\varepsilon$ model and RNG k- $\varepsilon$ model in this simulation.

\section{WIND FLOW AROUND CLUSTER OF EXISTING BUILDINGS}

In this study, the existing cluster of high-rise structures located in Mandalay depicted in Figure 4, consisting of L-shape building, Condo A, Condo B and Tower. The arbitrary domain size is shown in Figure 5 to simulate the building within the atmospheric boundary layer. The length of the simulation volume extends upstream of buildings over a distance of $5 \mathrm{H}$, downstream over a distance of $25 \mathrm{H}$, summaries side of the buildings over a distance of $10 \mathrm{H}$ and height of the domain size over a distance of $5 \mathrm{H}$, $\mathrm{H}$ being the height of the L-shape building, $45.7 \mathrm{~m}$. The full scale dimensions of the computational domain are $982.45 \mathrm{~m} \times$ $228.5 \mathrm{~m} \times 1464.8$ in lateral, vertical and flow directions respectively.

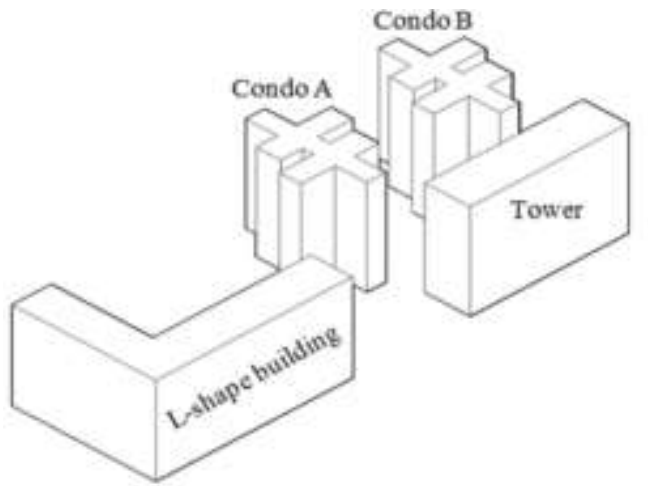

Figure 4. Existing cluster of structure

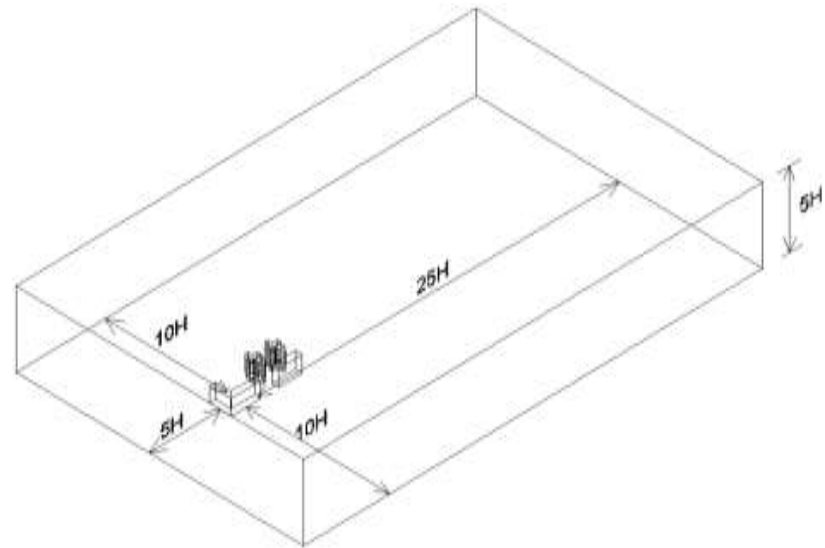

Figure 5. Arbitrary domain size

In Mandalay city, the most frequency percentage of wind direction is south wind direction and the second most frequency percentage is south-east direction. Therefore, the simulation has been carried out from south direction $\left(0^{\circ}\right)$ to south-east direction $\left(45^{\circ}\right)$ at the interval of $15^{\circ}$. Variations name of the different faces of the L shape building and different attack angles are shown in 
Figure 6. In these simulations, this mesh has over 2930000 nodes and over 285000 elements by using MultiZone Meshing Method. The maximum cell size for all three domains was $0.02 \mathrm{~m}$ and minimum cell size was $0.0001 \mathrm{~m}$. The basic wind speed, $\mathrm{U}_{\text {ref }}$, is $38.16 \mathrm{~m} / \mathrm{s}$ in Mandalay from Myanmar National Building Code (2016). The vertical profile for inlet boundary condition is show in Figure 7 and the summary of the data are similar with the previous CFD simulation.

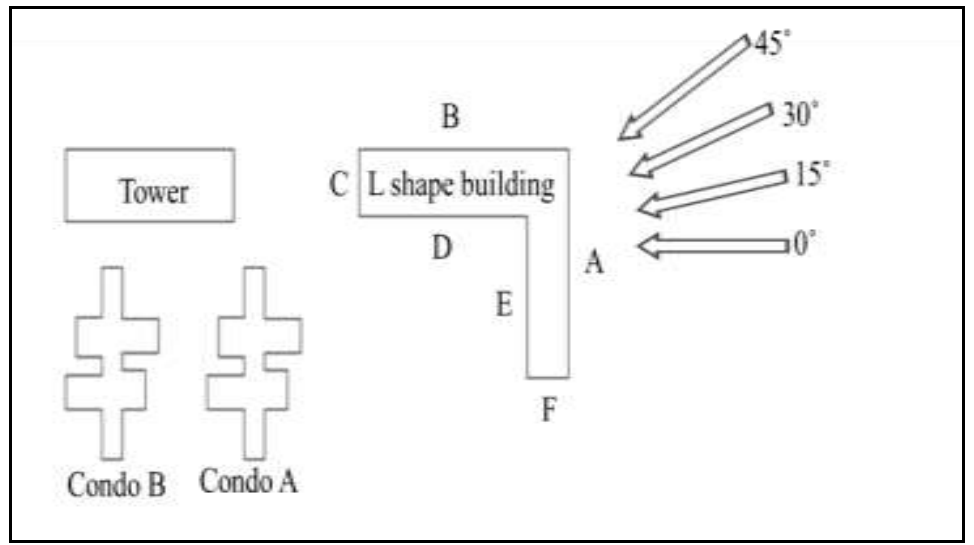

Figure 6. Name Of The Different Faces Of The Building and Different Attack Angles

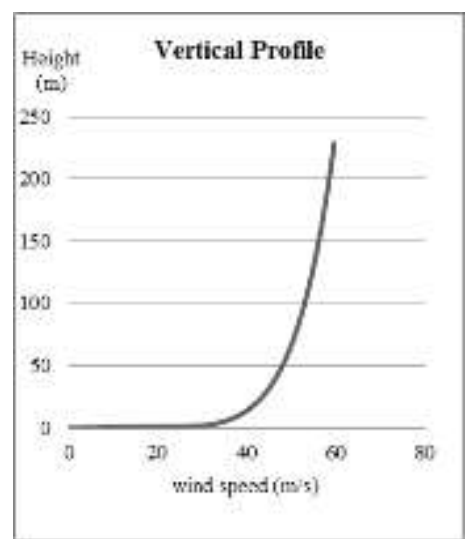

Figure 7. Vertical Profile for Inlet Boundary Conditions

\subsection{Stream line pattern of velocity with different attack angles}

To examine the airflow process, Figure 8 demonstrates the effect of wind direction on the stream line pattern of the velocity around the structures.

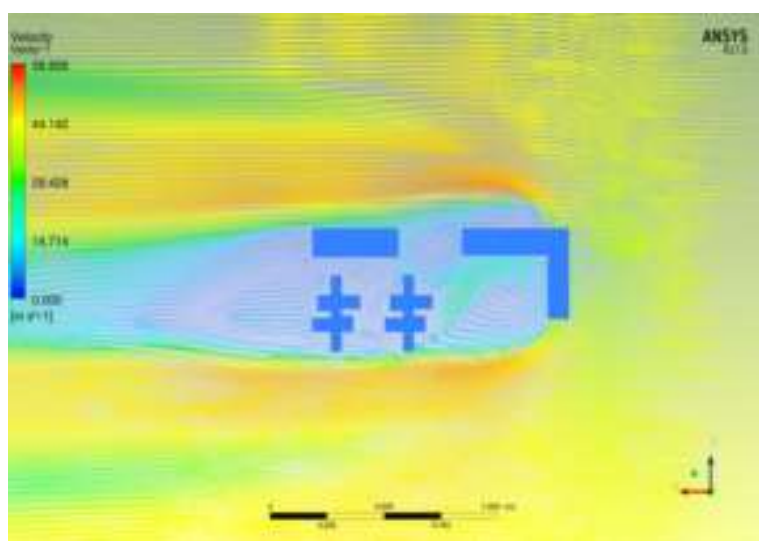

(a) $0^{\circ}$

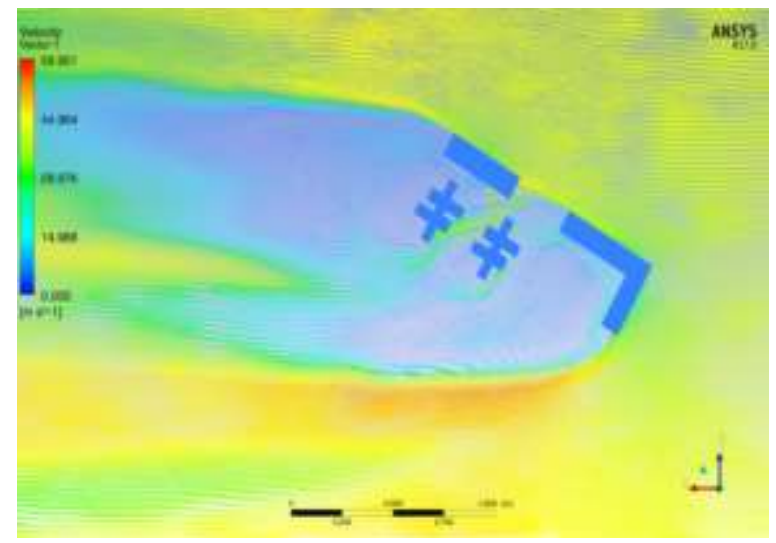

(a) $30^{\circ}$

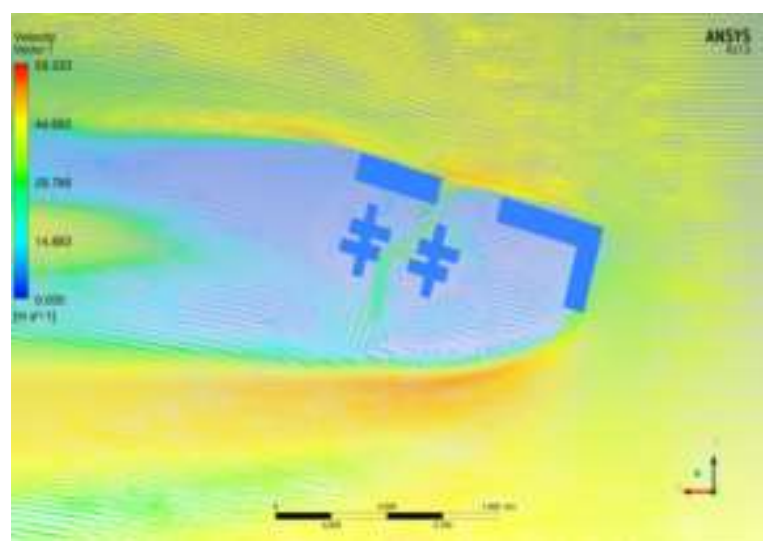

(b) $15^{\circ}$

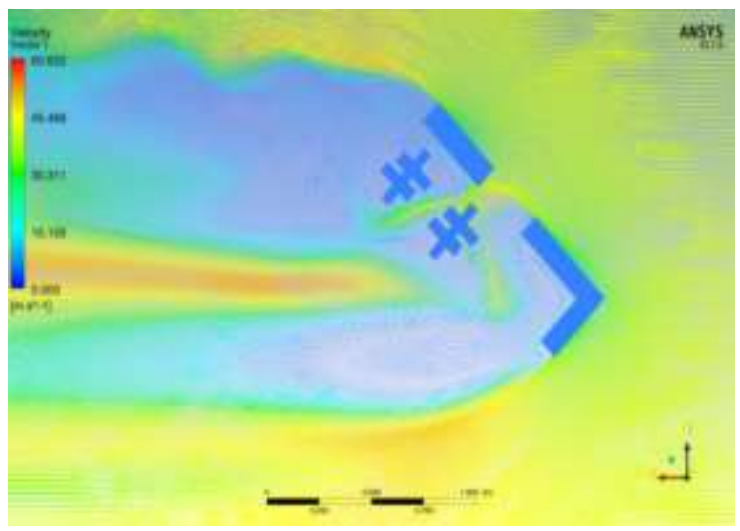

(d) $45^{\circ}$

Figure 8. Close up view of stream line pattern on the horizontal plane at the middle height of the L-shape building 
It can be clearly seen that at incident wind angle $0^{\circ}$, the flow comes to rest to form the front stagnation point at the center of the windward face of the L-shape building. From this point, the flow deviates into four main streams. Above this point, the first stream goes up and over the top of the L shape building. Below this point, the second flow goes down into the recirculation at the base of the windward face of the $\mathrm{L}$ shape building due to downwash effect. The third and fourth streams flow rapidly from there around the windward corners of the building. In Figures 8(a), especially, horseshoe vortices are occurred, one is counter clockwise in the front of the tower building and other is the clockwise at the central open space near the leeward side of L-shape building. High speed of recirculation flow occurred in the left side of the windward face of the Condo A due to backwash effect. In Figure 8(b), many vortices are formed. Horseshoe vortices are occurred near the left side of the condo A in the opposite direction. High speed of wind velocities are flowing the interval between Condo A and Condo B. In $30^{\circ}$ wind direction, recirculation flow occurred in the front of the tower building due to the backwash effect and a small vortex with clockwise direction are occurred near the back of the left corner of the Condo A building. The backwash flow from the Tower building are come to flow the leeward side of the L shape building with high wind speed. In Figure 8(d), the high stream lines velocity are entering into the right side of the Condo A building as obstacles on the wind pathway from the interval between Tower building and L-shape building. From the above flow visualization of the stream lines pattern, small vortices are occurred at the central part between Condo A, Condo B and Tower building in three different attack angles except $0^{\circ}$ wind direction.

\subsection{Contour map of velocity magnitude with different attack angles}

Figures 9, 10, 11 and 12 represent the comparison of velocity magnitude on the horizontal plane at four different height of the building for $0^{\circ}, 15^{\circ}, 30^{\circ}, 45^{\circ}$ wind angle. The four different height of the building is considered at (a) H, (b) H/2, (c) H/4 and (d) $\mathrm{H} / 6$, respectively.

It is observed that when the flow was approaching the solid buildings, the wind velocity is dramatically decreased to $6.54 \mathrm{~m} / \mathrm{s}$. The height level of the buildings decreases, the downwash wind flow area in the front of the L-shape building increases. For all section level in Figure 9, low wind speed areas are found in the back of buildings and in the place of the two vortices center. In Figure 9 (b), the high wind speed area with velocity $39.238 \mathrm{~m} / \mathrm{s}$ are formed at the central open space near the leeward side of the L-shape building due to withdrawal of the building.

It can be clearly seen that low speed area with deep blue color are formed around the left side of the Condo A building and behind the Tower building as shown in Figure 10 (a). In figure 10 (b), the large low speed area with velocity $39.689 \mathrm{~m} / \mathrm{s}$ are found the interval between Condo A and Condo B. In Figure 10 (c) and (d), the low speed areas are decreased around the Condo A building and the wind speed area with velocity about $46.303 \mathrm{~m} / \mathrm{s}$ are found near the right side of the L shape building and Tower building. For all section level, wind flow are entering from the front of the Tower building toward the right side of the Condo A building due to recirculation flow.

In $30^{\circ}$ wind direction, it can be clearly seen that the low speed areas more reduce than above the wind incidence $0^{\circ}$ and $15^{\circ}$ angles as shown in Figure 11 and the low wind velocities with about $6.861 \mathrm{~m} / \mathrm{s}$ are formed behind the Condo B building. In Figure 11 (a), high wind speeds about $39.968 \mathrm{~m} / \mathrm{s}$ are found in the front of the Condo A buildings. High wind speed areas with about $33.306 \mathrm{~m} / \mathrm{s}$ are occurred near the interior side of the $\mathrm{L}$ shape building due to the backwash flow. At the low level facilities, high wind speed areas with about $46.629 \mathrm{~m} / \mathrm{s}$ are occurred near the right side back of the $\mathrm{L}$ shape building and Tower building as shown in Figure $11(\mathrm{~d})$.

It can be observed that the low speed areas are the smallest place other than the wind directions as shown in Figure 12. The front stagnation point is formed in the front corner of the $\mathrm{L}$ shape building at incident wind angle $45^{\circ}$. For low level section at height $\mathrm{H}$, high wind speed areas with about $53.686 \mathrm{~m} / \mathrm{s}$ are found in the right side back of the L shape building and behind the left side of the Condo A. At 45 degree wind direction, the wind flowed entering from the interval between the L-shape building and Tower building into right side of the Condo A building with the velocity increased up to $40.415 \mathrm{~m} / \mathrm{s}$. Therefore, high wind speed areas are found in the central open space due to back flow from the front of the Tower and Condo A building. 
International Journal of Engineering Research And Advanced Technology, Vol.5, Issue 3, March-2019

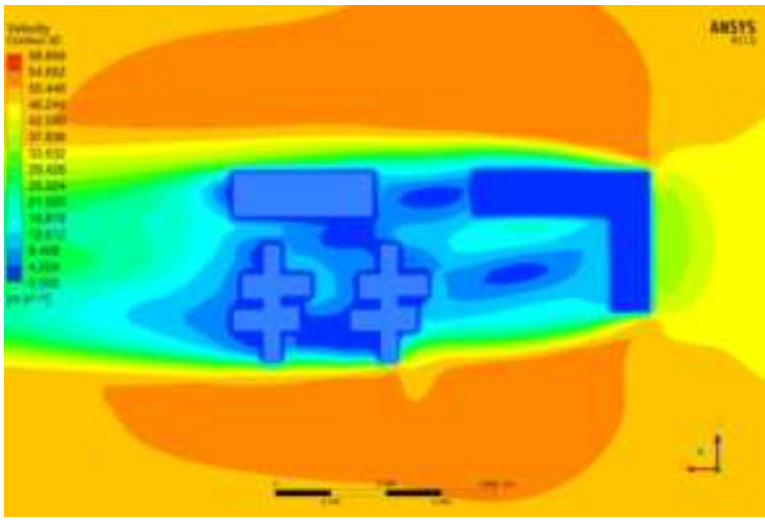

(a)

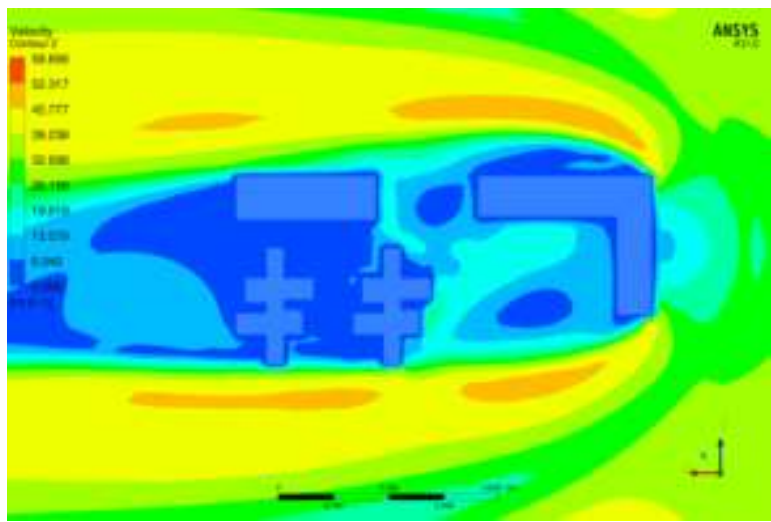

(c)

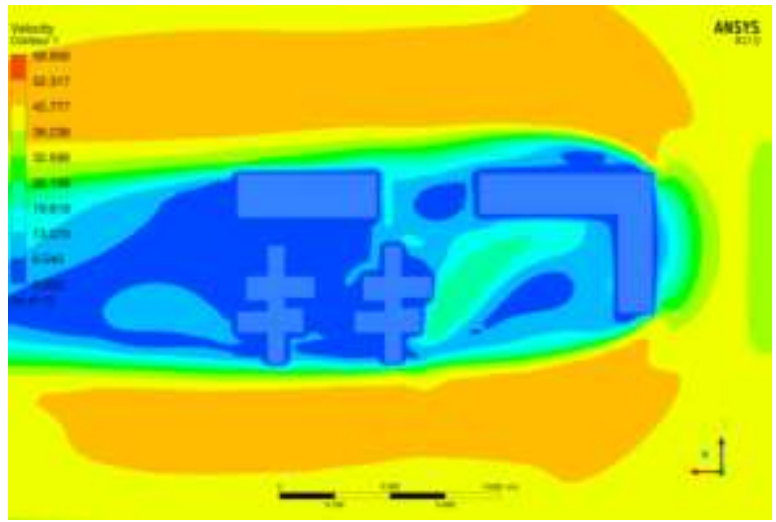

(b)

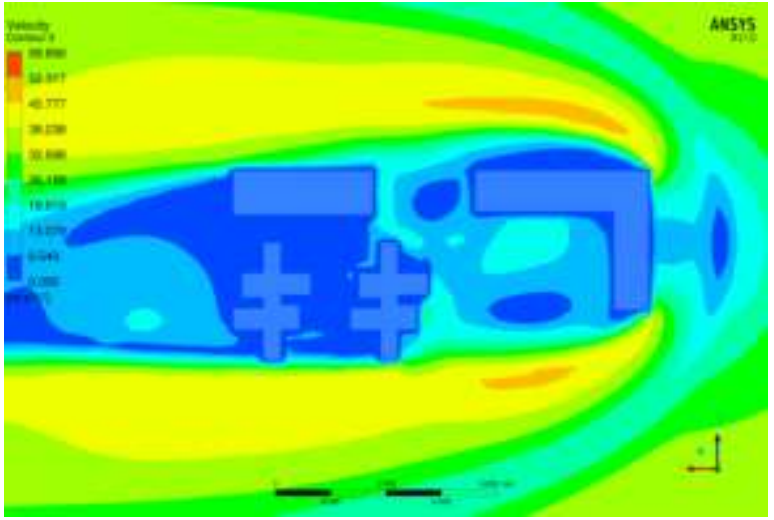

(d)

Figure 9. Close up view of Velocity magnitude (m/s) on the horizontal plane at (a) $H$ (b) $H / 2$ (c) $H / 4$ (d) $H / 6$ for $0^{\circ}$ wind angle.

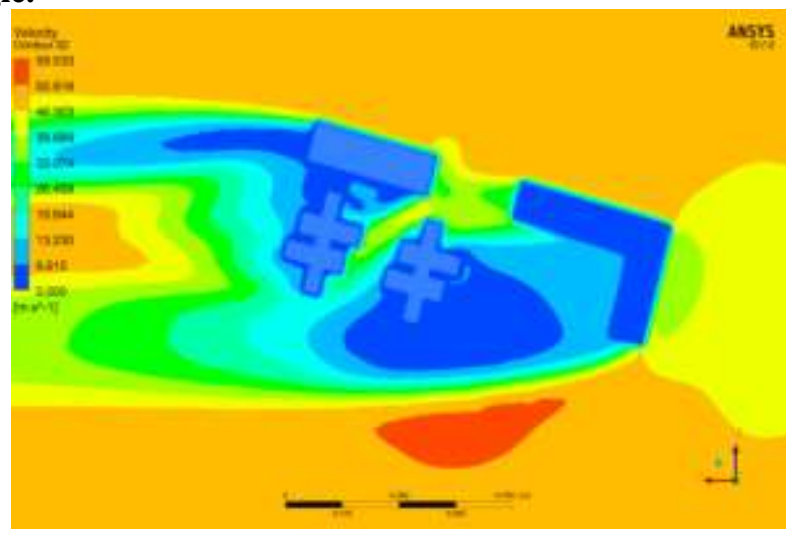

(a)

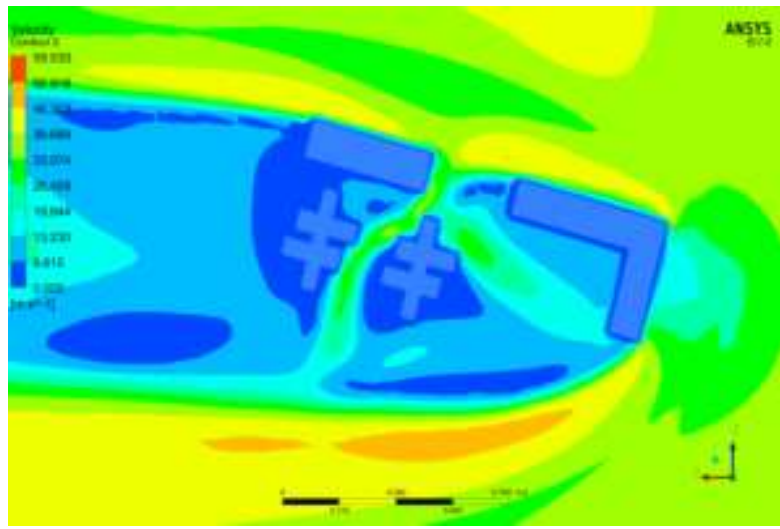

(c)

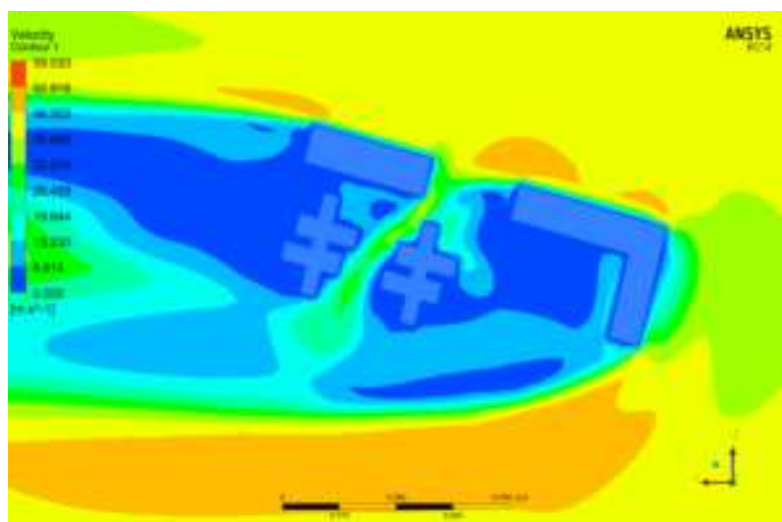

(b)

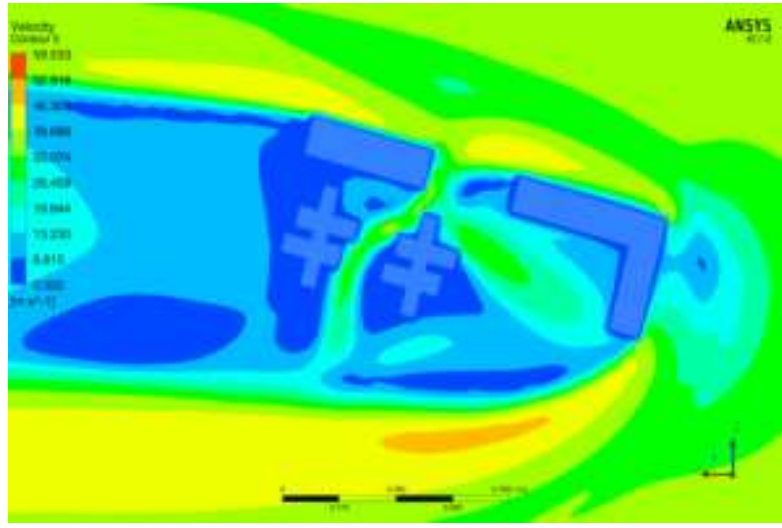

(d)

Figure 10. Close up view of Velocity magnitude (m/s) on the horizontal plane at (a) H (b) H/2 (c) H/4 (d) H/6 for a wind incidence angle of $15^{\circ}$ 
International Journal of Engineering Research And Advanced Technology, Vol.5, Issue 3, March-2019

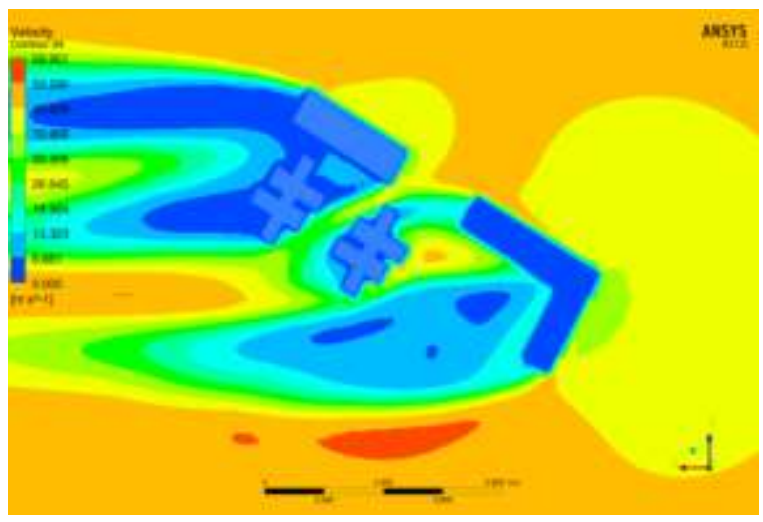

(a)

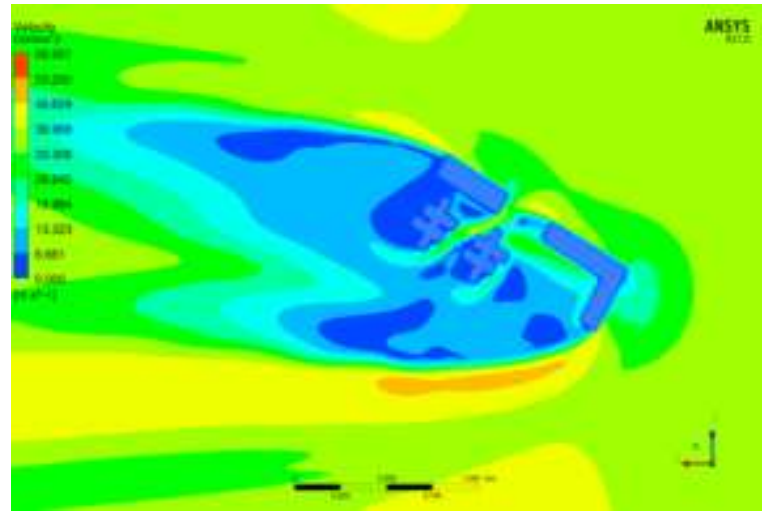

(c)

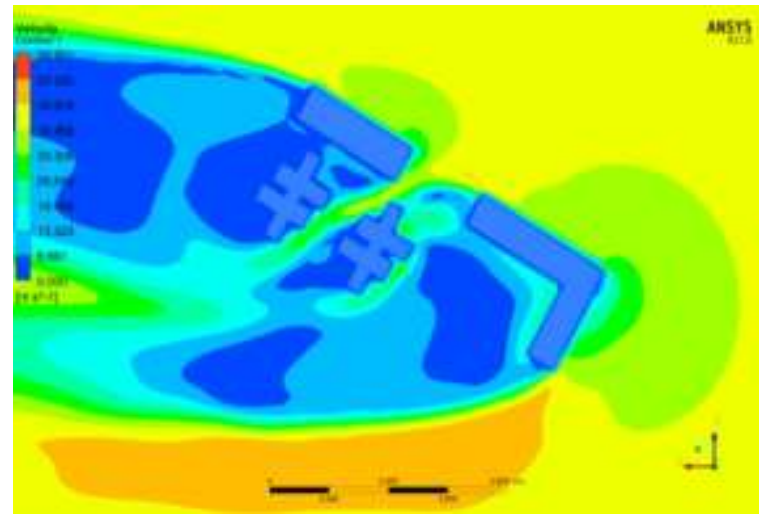

(b)

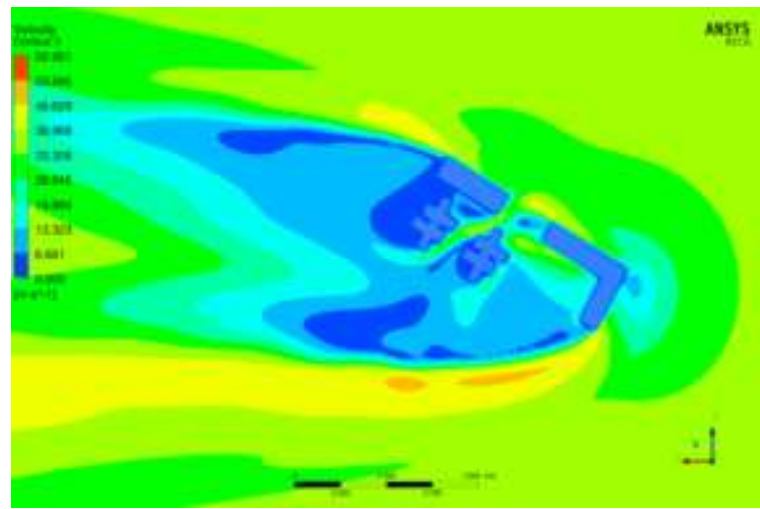

(d)

Figure 11. Close up view of Velocity magnitude (m/s) on the horizontal plane at (a) $H$ (b) H/2 (c) H/4 (d) H/6 for a wind incidence angle of $30^{\circ}$

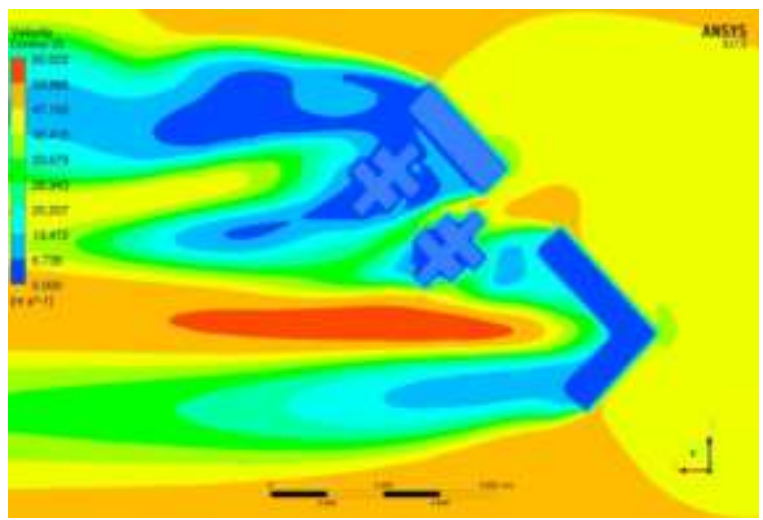

(a)

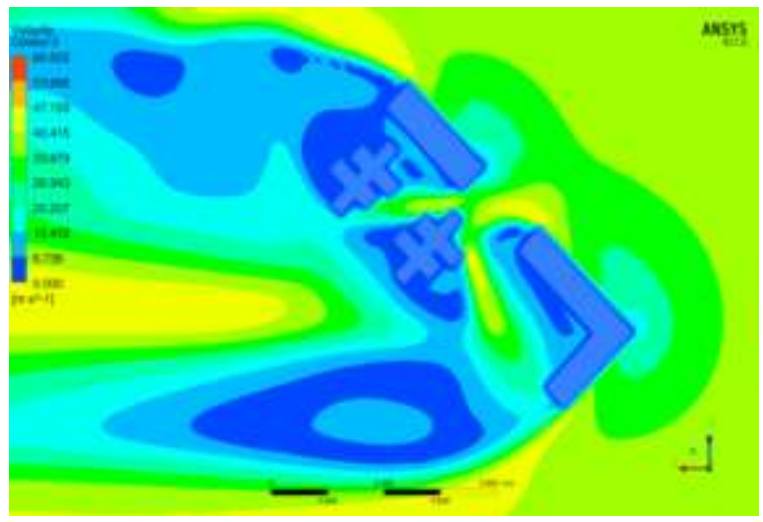

(c)

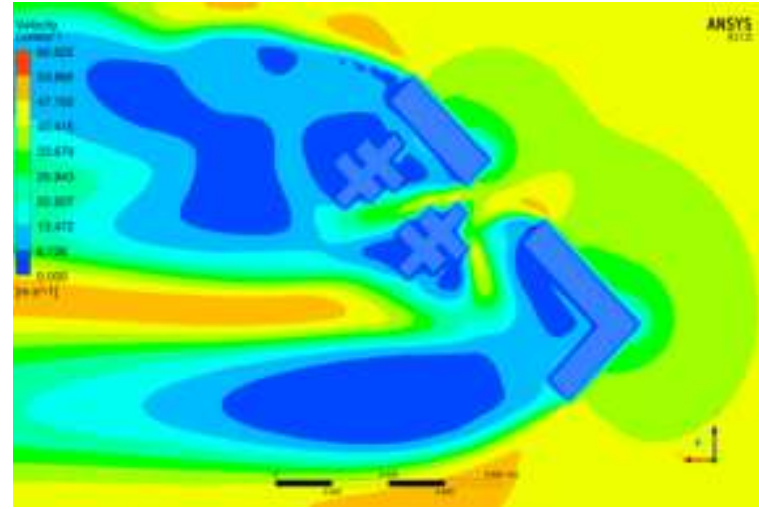

(b)

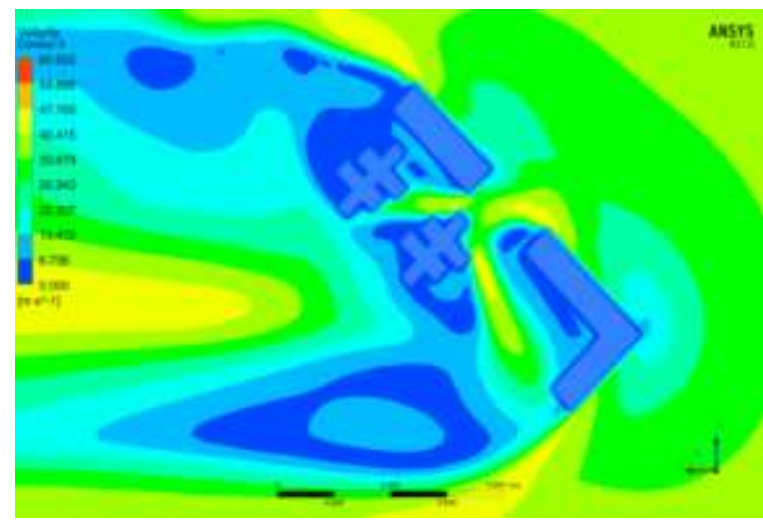

(d)

Figure 12. Close up view of Velocity magnitude (m/s) on the horizontal plane at (a) H (b) H/2 (c) H/4 (d) H/6 for a wind incidence angle of $\mathbf{4 5}^{\circ}$ 


\subsection{Comparisons of Pressure Coefficients on the Various Faces of the L-Shape Building for Various Wind Angles}

The windward faces are subjected to positive pressure coefficients because of the undeviating wind force. Because of frictional flow separation and generation of vortices, the leeward faces are exposed to suction pressure.

Variation of pressure coefficients along the vertical centerline on various faces of the $\mathrm{L}$ shape building for $0^{\circ}, 15^{\circ}, 30^{\circ}$ and $45^{\circ}$ wind incidence angles are demonstrated in Figures 13. The vertical coordinate represents height of the L shape building in meter and the horizontal coordinate represents value of pressure coefficient $(\mathrm{Cp})$.

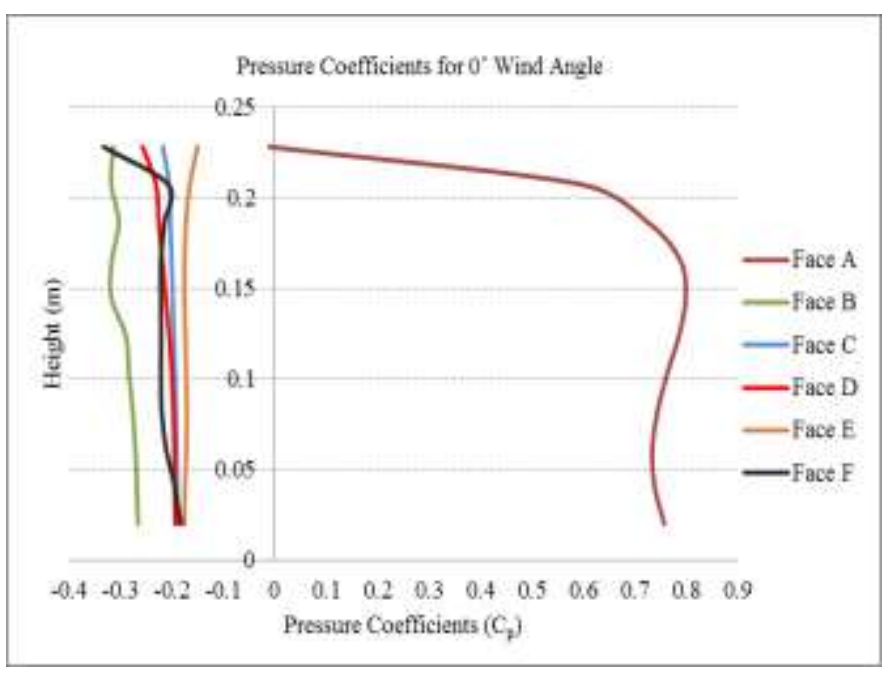

(a)

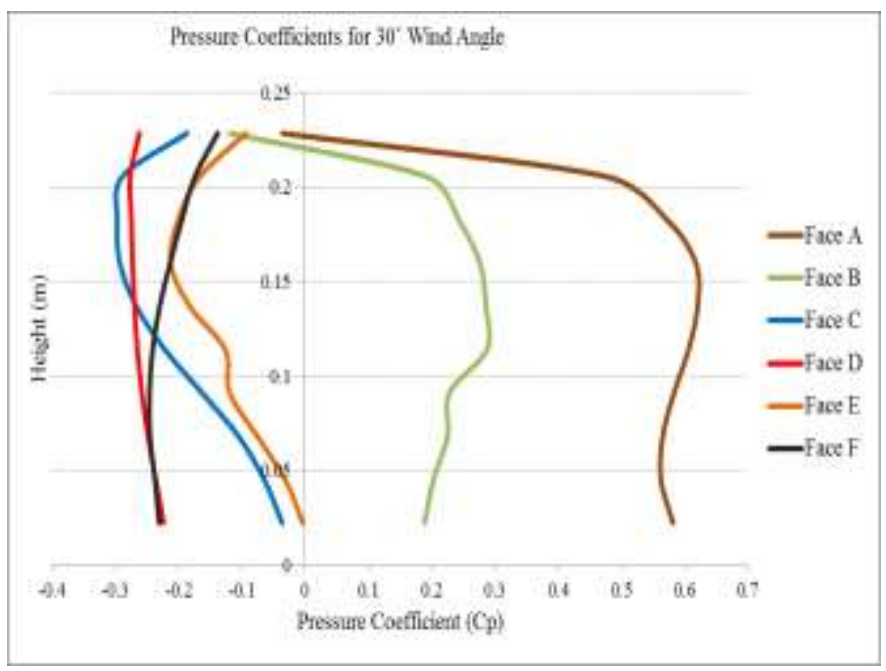

(c)

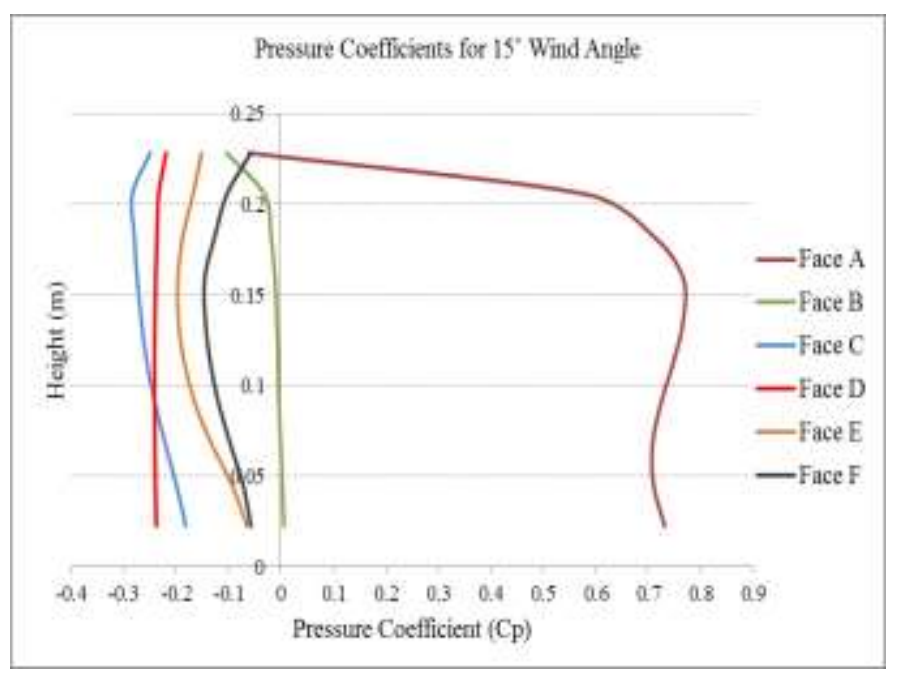

(b)

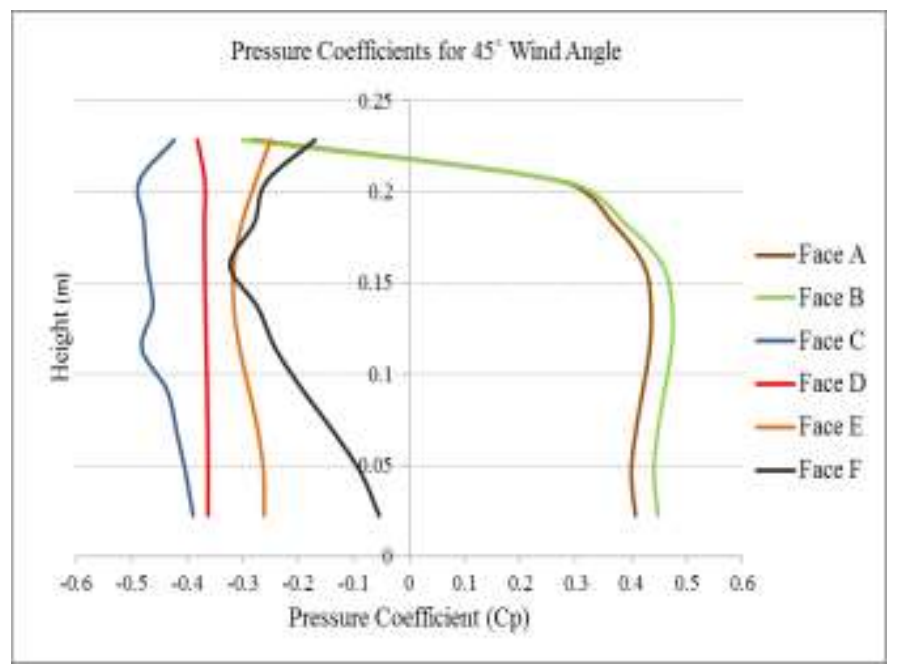

(d)

Figure.13. Variation of Pressure Coefficients along the Vertical Centerline on Various Faces of the $L$ shape building for (a) $0^{\circ}$ Wind Incidence Angle (b) $15^{\circ}$ Wind Incidence Angle (c) $30^{\circ}$ Wind Incidence Angle (d) $45^{\circ}$ Wind Incidence Angle

The nature of deviation of external pressure coefficients along the height of the building as well as along the perimeter of the building for different wind angles of attack is presented. Variation of pressure coefficient along the four horizontal lines for all faces of the $\mathrm{L}$ shape building at wind incidence angles $0^{\circ}, 15^{\circ}, 30^{\circ}, 45^{\circ}$ are shown in Figure 14 . Four different heights of the building are considered to take into account the variation along the height as well. The perimeter of four different heights of the building are $10 \%$ of the height of the L shape building $(0.1 \mathrm{H}), 30 \%$ of the height of the L shape building $(0.3 \mathrm{H}), 50 \%$ of the height of the L shape building $(0.5 \mathrm{H})$, and $80 \%$ of the height of the $\mathrm{L}$ shape building $(0.8 \mathrm{H})$.

The ordinate of the graph is the external pressure coefficient $(\mathrm{Cp})$ of each face and along the abscissa the perimeter of the building is plotted. These plots support understanding the overall scenario, i.e., the response of all the faces of the building under a particular wind incidence angle. 


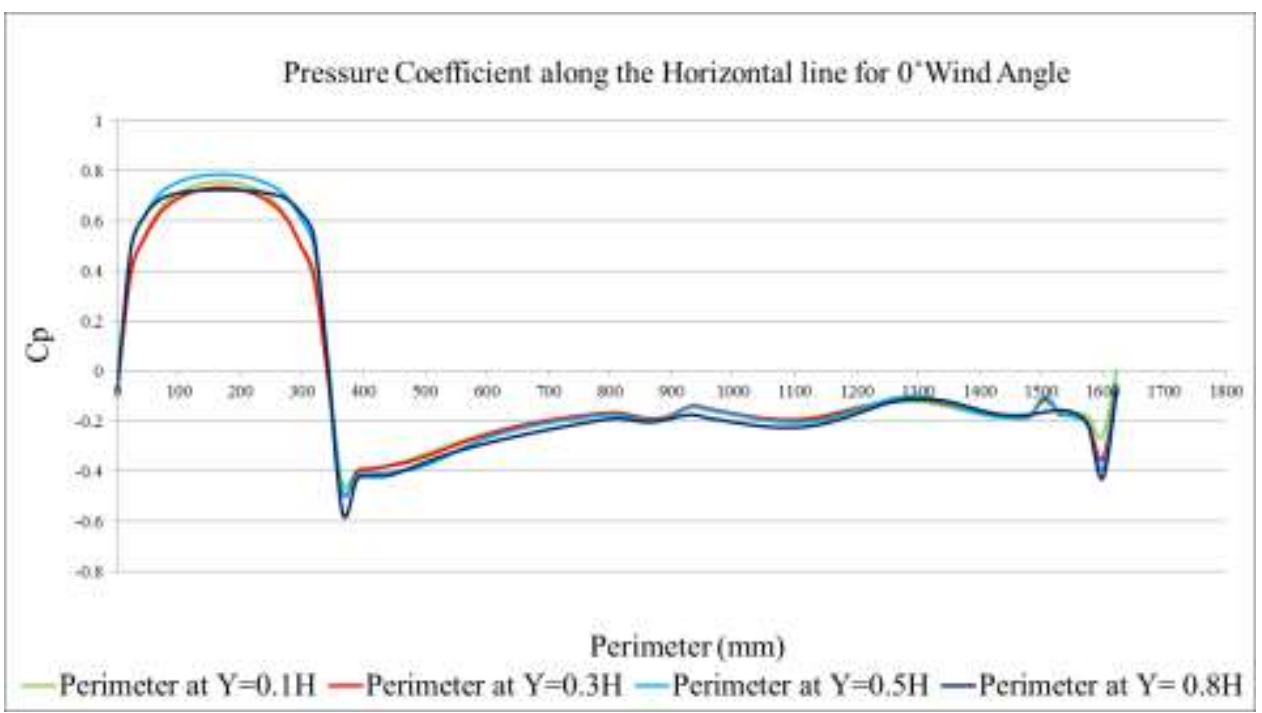

(a)

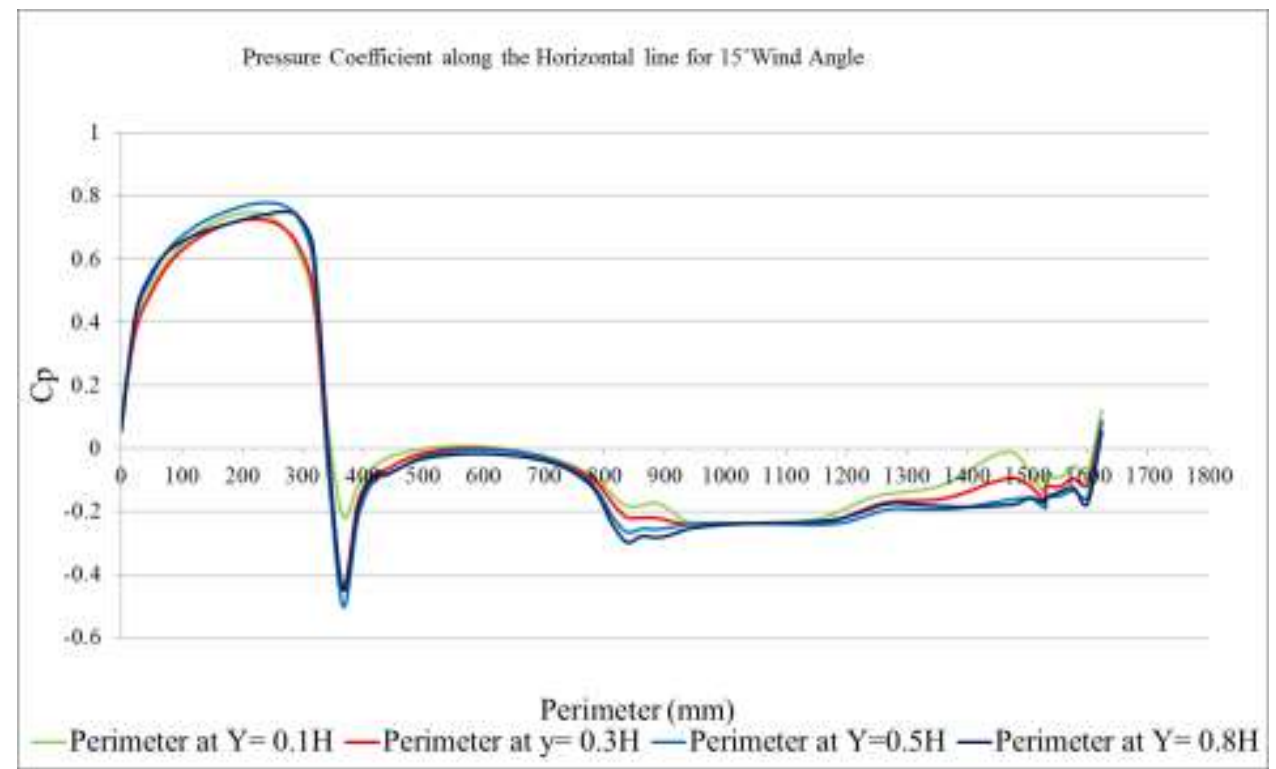

(b)

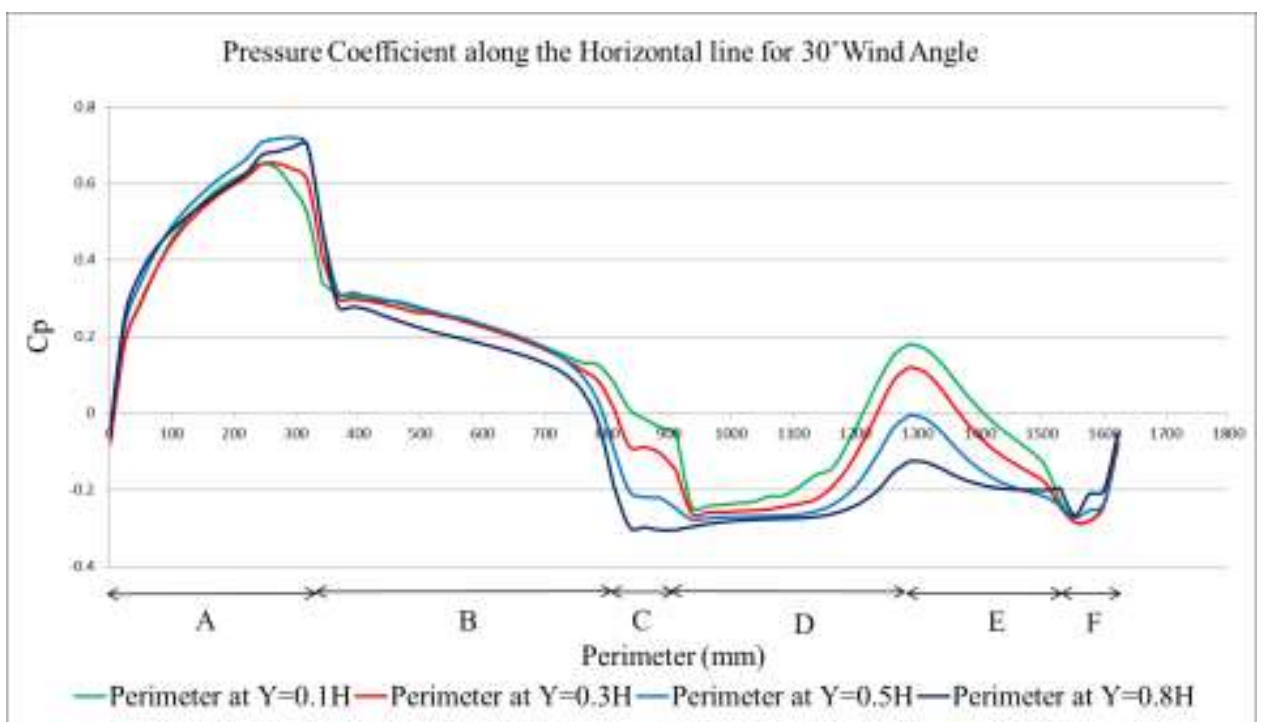

(c) 


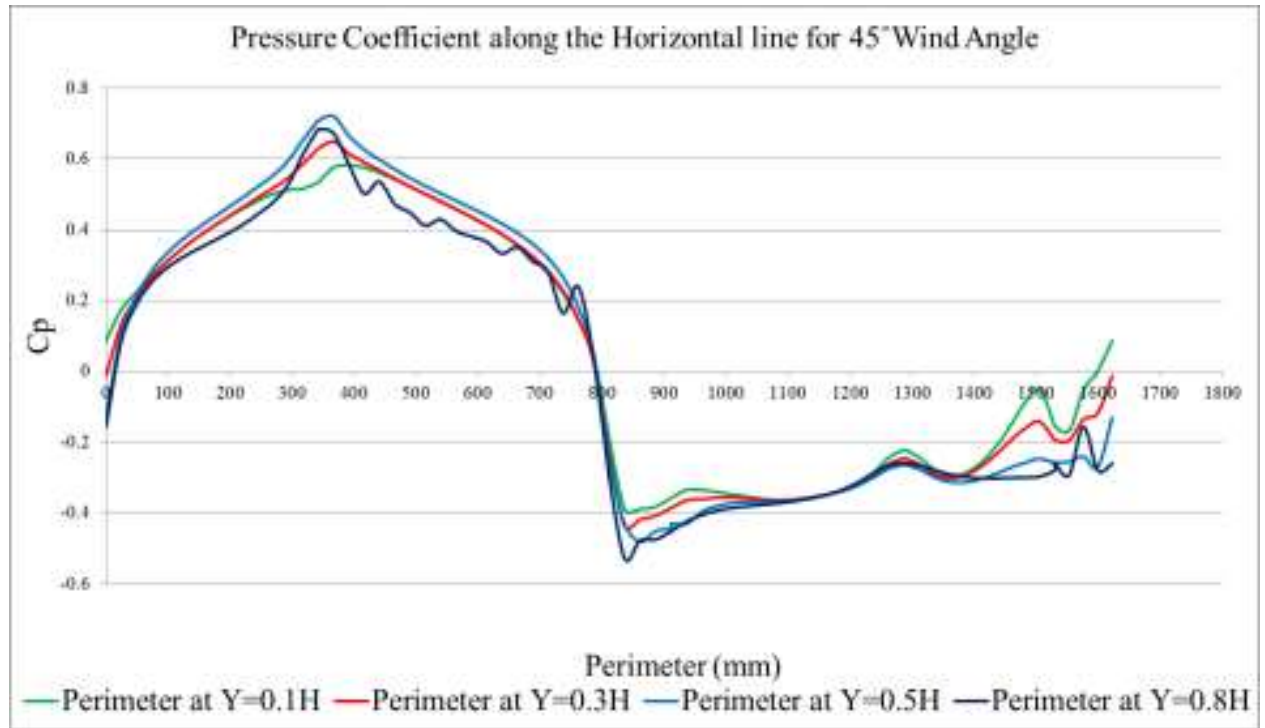

(d)

Figure 14. Variation of Pressure Coefficients along the four Horizontal Lines on Various Faces of the $L$ shape building for (a) $0^{\circ}$ Wind Incidence Angle (b) $15^{\circ}$ Wind Incidence Angle (c) $30^{\circ}$ Wind Incidence Angle (d) $45^{\circ}$ Wind Incidence Angle

\subsection{Comparison of maximum wind pressure coefficients}

The comparison of maximum wind pressure coefficients on the various faces of the $\mathrm{L}$ shape building for wind angles $0^{\circ}, 15^{\circ}, 30^{\circ}$ and $45^{\circ}$ are listed in Table 2. Positive pressure coefficients occur at the windward faces due to direct wind dissipation and suction pressure form at the leeward faces because of frictional flow separation and vortex generation.

Table 2. Surface pressure coefficients for the $L$ shape building

\begin{tabular}{|c|c|c|c|c|}
\hline \multirow{2}{*}{$\begin{array}{c}\text { Faces of } \\
\text { the building }\end{array}$} & \multicolumn{5}{|c|}{ Pressure Coefficient, $\mathbf{C}_{\mathbf{p}}$ (face maximum value) for different wind } \\
\cline { 2 - 5 } & $\mathbf{0}^{\circ}$ & $\mathbf{1 5}^{\circ}$ & $\mathbf{3 0}^{\circ}$ & $\mathbf{4 5}^{\circ}$ \\
\hline Face- A & 0.799 & 0.804 & 0.744 & 0.726 \\
\hline Face- B & -0.57 & -0.5 & 0.5 & 0.73 \\
\hline Face- C & -0.23 & -0.3 & -0.31 & -0.54 \\
\hline Face- D & -0.26 & -0.28 & -0.3 & -0.45 \\
\hline Face- E & -0.19 & -0.2 & -0.25 & -0.32 \\
\hline Face- F & -0.43 & -0.17 & -0.29 & -32 \\
\hline
\end{tabular}

For all wind angles, Face A is positive pressure coefficient because of windward face of the building. The highest value of pressure coefficient is about 0.804 for a $15^{\circ}$ wind angle. Face B is suction pressure in wind angles of $0^{\circ}$ and $15^{\circ}$. For the wind incidence angles of $30^{\circ}$ and $45^{\circ}$, Face B becomes windward face and is subjected to positive pressure. Face C, Face D, Face E and Face $\mathrm{F}$ are exposed to suction pressure and Face E suffers the lowest suction pressure for all consider wind angles.

\section{CONCLUSIONS}

This paper discusses the comparison of different turbulence models in simulating wind environment around building complexes. Information of wind pressure and air flow pattern can be provided to the designers at the early stage of design. CFD simulation is a more cost-effective and time-saving design tool for wind engineering studies. This simulation has been carried out to study the 
effect of wind direction on velocity distribution around the structures wind directions. Numerical simulations have been performed at $0^{\circ}, 15^{\circ}, 30^{\circ}$, and $45^{\circ}$ wind angles using Realizable K- $\varepsilon$ turbulence models with standard wall function. For the wind directions $0^{\circ}, 15^{\circ}$ and $30^{\circ}$, the layout of existing cluster of buildings is good enough for building planners to take critical decision such as exterior layout of building, building spacing by wind flow pattern. In this layout of existing cluster of building, Condo A has located along the wind pathway entering from the interval between the L-shape building and Tower building especially at the wind incidence angle $45^{\circ}$. So, Condo $\mathrm{A}$ is not good for pleasant ambience. The windward faces are subjected to positive pressure coefficients because of the undeviating wind force. Because of frictional flow separation and generation of vortices, the leeward faces are exposed to suction. Flow separation characteristics and vortices are quite apparent from the streamlines. When a new building is planned, the design should consider the wind environment created by the surrounding buildings.

\section{ACKNOWLEDGMENT}

The author would like to Dr.San Yu Khaing, Professor, Department of Civil Engineering, Mandalay Technological University for her enthusiastic instruction, invaluable help, and indispensable guidance in the preparation of this paper.

\section{REFERENCES}

[1] S., Bungale, Taranath Ph.D., S.E, john A, Martin \& Associates, Inc, Wind and Earthquake Resistant Buildings, Los Angeles, California, 2005.

[2] Daeung Kim. The Application of CFD to Building Analysis and Design: A Combined Approach of an Immersive Case Study and Wind Tunnel Testing. Thesis (PhD), Architecture and Design Research, Blacksburg, Virginia, 2013.

[3] Garatt, J. R., Hess, G. D., Physick, W. L, Bougeault, P., "The Atmospheric Boundary Layer - Advances in Knowledge and Applications, Boundary Layer Meteorology", pp. 9 - 37, 1996.

[4] J., Franke, "Recommendations of the cost action c14 on the use of CFD in predicting pedestrian wind environment", In: the 4th International Symposium on Computational Wind Engineering, Japan Association for Wind Engineering, Yokohama, pp.529-532, 2006.

[5] F., Baetke, H., Warner, (1990), "Numerical Simulation of Turbulent Flow over Surface Mounted Obstacle with Sharp Edges and Corners", Journal of Wind Engineering and Industrial Aerodynamics, Vol.35, pp.129-147, 1990.

[6] H, K., Veersteeg, W., Malalasekara, W., An Introduction to Computational Fluid Dynamic, Prentice Hall,1995.

[7] B., Blocken, J., Carmeliet, T., Stathopoulos, "CFD Evaluation of the Wind Speed Conditions in passages between BuildingsEffect of Wall-function Roughness Modifications on the Atmosphere Boundary Layer Flow", Journal of Wind Engineering and Industrial Aerodynamics, Vol.95, pp.941-962, 2007. 